\title{
Resveratrol Attenuates LPS-induced Apoptosis via Inhibiting NF-KB Activity in Chicken Peripheral Lymphocyte Cultures
}

\section{-Author(s)}



College of Biology Engineering, Henan University of Technology, Zhengzhou 450001, P. R. China.

College of Livestock Husbandry and Veterinary Engineering, Henan Agricultural University, Henan Research Center of Breeding Resources for Poultry, Zhengzhou 450002, P. R. China.

\section{a Mail Address}

Corresponding author e-mail address Jin Huang

College of Biology Engineering, Henan University of Technology, Zhengzhou 450001, P. R. China.

Phone: (86)-0371-67756513

Email: 18623718380@163.com

\section{aKeywords}

Resveratrol; NF-KB; lymphocyte apoptosis; chicken.

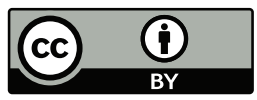

Submitted: 29/December/2017 Approved: 10/June/2018

\section{ABSTRACT}

This study aims to investigate whether resveratrol (RES) could inhibit NF-kB activity and protect in vitro cultured chicken lymphocytes from apoptosis induced by continuous LPS stimulation. Blood lymphocytes of chickens were collected and cultured. LPS was added to the samples of treatment group, while the same volume of normal saline (NS) was supplemented to those of the control group. In the treatment groups, four different concentrations of RES $(0,20,40$, and $80 \mu \mathrm{g} / \mathrm{ml})$ were admixed. Then, the following indicators were tested: lymphocyte apoptotic rate, lymphocyte viability, NF-kB activity, TNF- $\alpha$ level, reactive oxygen species (ROS), and expression of apoptosis-related proteins (Fas/FasL and Caspase-8). The results indicated that the application of different concentrations of RES could significantly increase the viability of lymphocytes and decrease the apoptotic rate $(p<0.05)$ after continuous stimulations by LPS. The activity of NF-kB levels of TNF- $\alpha$ and ROS in the RES treatment subgroups was significantly decreased in comparison with that in the RES-blank subgroup $(p<0.05)$. The cells in the treatment group that had been treated with 20,40 and $80 \mu \mathrm{l} / \mathrm{ml}$ of RES exhibited a significantly lower Fas and Caspase-8 expression level than that in the RES-blank subgroup $(p<0.05)$. These findings revealed that RES could substantially diminish the concentrations of ROS and TNF- $\alpha$, down-regulate NF-KB activity, decrease the expression of Fas and Caspase-8, stimulate the activity of peripheral lymphocytes, and lower the rate of their apoptosis, induced by continuous LPS stimulation in chicken lymphocyte cultures.

\section{INTRODUCTION}

Pathogen activity, including the effect of the bacterial product lipopolysaccharide (LPS), can induce cellular immune responses to over activate lymphocytes and initiate the production of a great number of inflammatory factors (Zhang, 2017; Spurlock, 1997; Shini et al. 2008) and reactive oxygen species (Ben et al., 1999). Infection with LPS ultimately leading to structural damages of the lymphocytes and their apoptosis (Rodrigues et al., 1999; Watanabe et al., 2003), and the consequent decrease in lymphocyte count and immune functions (Lappin \& Ferguson, 2009). The methods examined and utilized to improve the immune functions of the body through the reduction of the inflammatory responses and lymphocyte apoptosis induced by immune stressor factors, including the application of LPS, have gained an ever-increasing research interest. Previous studies showed that the mechanisms participating in the stimulation of inflammatory responses and lymphocyte apoptosis induced by LPS, were involved in the initiation of a nuclear transcription factor - the карра B (NF-кB) 
signaling pathway (Lawrence, et al., 2005). NF-кB is an important nuclear transcription factor with extensive regulatory biological functions, which can activate the transcription of multiple genes and play crucial roles in the inflammatory responses, oxidative stress (Zhang et al., 2013), and cellular apoptosis (Manna et al., 2000; Barkett et al., 1999). Fas receptor-mediated Caspase-8 activation is an important pathway of cellular apoptosis.

Resveratrol (RES) is a natural polyphenol compound with anti-inflammatory effects (Shakibaei et al., 2008) that reduces cellular oxidative stress (Wang et al, 2017; Yun et al., 2012), and protects the cells from damages or apoptosis (Hsieh et al., 2002; Seo et al., 2014). Earlier investigations demonstrated that RES inhibited the activation of NF-kB (Yi et al., 2011; Tsai et al., 1999). However, only a very limited number of examinations in domestic fowls have been performed. The activation of NF-KB induces the transcription of anti-apoptotic or pro-apoptotic genes, which is dependent on the differences of the stimuli and the cell types. In recent years, several studies were conducted, focusing mainly on the antioxidative effects of RES on domestic fowls. For example, it was revealed that the utilization of $400 \mathrm{mg} / \mathrm{kg}$ of RES could effectively improve the antioxidative status in chickens and eggs (Sahin, et al. 2010). In another investigation, the daily administration of RES was found to reduce the oxidative stress in domestic fowls and to protect their liver cells (Sahin, et al. 2012). In the present study, we aimed to explore the molecular mechanisms involved in the protective action of RES on the apoptosis of lymphocytes and provide exact theoretic evidence for the regulation of the immunological stress-induced lymphocyte apoptosis in animals.

\section{MATERIALS AND METHODS}

\section{Isolation and culture of lymphocytes}

Specific Pathogen-Free 1-day-old hybrid chickens (Luo Dao Hong×White Lai Hang) were selected from the experimental chicken farm of Henan Agricultural University and fed ad libitum with a standard diet formulated to meet the nutrient requirements as recommended by the National Research Council. At 2 weeks of age, six birds were anesthetized using urethane and bled by cardiac puncture using a heparinized syringe. All experiments were approved by the Science and Technology Department of Henan Province Animal Care and Use Committee.
Peripheral blood was collected from the heart of these chickens, and the lymphocytes were isolated. In brief, $3 \mathrm{ml}$ of fresh anticoagulant blood was mixed with Hank's solution (1:1), and then $2 \mathrm{ml}$ of the lymphocyte separation liquid was carefully added to the surface of the mixed liquid. A centrifugation was performed at $1500 \mathrm{rpm}$ for $15 \mathrm{~min}$, on a rotator with a radius of $15 \mathrm{~cm}$; then, a capillary pipette was used to carefully collect the PBMC layer (the second layer) along the tube wall to draw the lymphocytes. Afterwards, the cells were washed with Hank's solution, centrifuged at $1800 \mathrm{rpm}$ for $10 \mathrm{~min}$; the supernatant was discarded, washed again, centrifuged at $1400 \mathrm{rpm}$ for $10 \mathrm{~min}$, and then discarded again). The isolated lymphocytes were cultured in the presence of PHA. On the second day after the incubation, LPS (a final concentration of $10 \mu \mathrm{l} / \mathrm{ml}$ ) was added to the four treatment group samples, while the same volume of normal saline (NS) was added to the control group. The four treatments were with four different concentrations of RES ( 0 , 20,40 , and $80 \mu \mathrm{g} / \mathrm{mL}$ ), respectively. There were 6 replicates, 3 triplicates, in each treatment. The lymphocytes were cultured at $37{ }^{\circ} \mathrm{C}, 5 \% \mathrm{CO}_{2}, 95 \%$ $\mathrm{O}_{2}$, and $\mathrm{pH}$ of 7.0-7.2 for $72 \mathrm{~h}$. Then, $30 \mathrm{ul}$ of the culture medium was collected from each well for the measurements.

\section{Estimation of the apoptotic rate of the lymphocytes}

The apoptotic rate of the lymphocytes was measured via in situ terminal deoxynucleotidyl transferasemediated nick end labeling (TUNEL). In a few words, the cell suspension was collected and washed with PBS, and then a $4 \%$ paraformaldehyde solution was used to fix the cells for 30-60 min. During the fixation, the cells were shaken gently to avoid cell agglomeration. Next, they were washed twice with pure PBS, and PBS containing $0.1 \%$ of Triton $\mathrm{X}-100$ was employed to resuspend the cells, followed by incubation in ice for 2 min. TdT enzyme and a fluorescent labeling solution (FITC) were utilized to prepare the TUNEL detecting solution, $50 \mu \mathrm{l}$ of which was added to each well, and then the cells were incubated at $37{ }^{\circ} \mathrm{C}$ for $60 \mathrm{~min}$. After the cells were washed twice with PBS, 250-500 $\mu \mathrm{l}$ PBS was used to suspend the cells, and then a flow cytometer was used to estimate the apoptotic rate of the cells Fig. 1 at an excitation wavelength of 450 $500 \mathrm{~nm}$ and an emission wavelength of 516-565 nm (green fluorescence). 


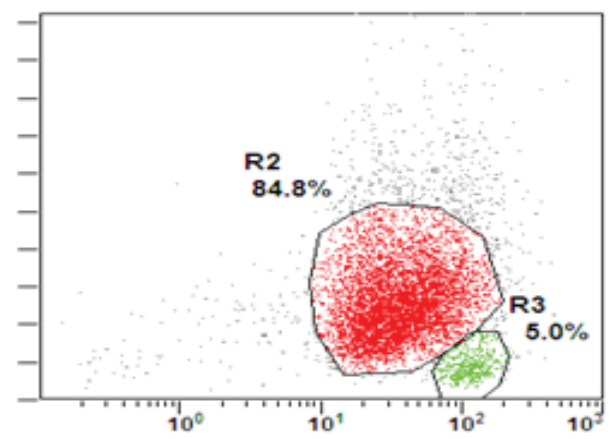

Figure 1 - One of the results of the TUNEL detection by flow cytometry method

\section{Evaluation of the viability of lymphocytes}

The lymphocyte transformation rate was measured by the MTT [3-(4,5-dimethylthiazol-2-yl)2,5-diphenyltetrazolium bromide colorimetric assay] method as follows:

1) Preparing MTT solution: $25 \mathrm{mg}$ of MTT was dissolved in $5 \mathrm{ml}$ of MTT solvent to obtain $5 \mathrm{mg} / \mathrm{ml}$ of MTT solution. The solution could be used immediately or stored at $-20^{\circ} \mathrm{C}$ in the dark; 2) 2000 cells $(100 \mu \mathrm{l})$ were added into each well; 3) $10 \mu \mathrm{l}$ MTT solution was added into each well, and then the cells were incubated for $4 \mathrm{~h}$.4) $10 \mu \mathrm{l}$ of Formanzan dissolve solution was added into each well, and then the cells were incubated until the Formanzan was found completely dissolved under a microscope (generally, the incubation at $37^{\circ} \mathrm{C}$ for 4h could completely dissolve the Formanzan; however, the time could also vary along with the amount of purple crystals; 5) The optical density (OD) at $570 \mathrm{~nm}$ was measured to determine the cell proliferation level.

\section{NF-KB and TNF- $\alpha$ assessments}

The activity of NF-kB in the cell nucleus was measured through the transfer of the p65 subunit into the cell nucleus by immunofluorescent staining by the use of NF-kB Activation-Nuclear Translocation Assay kits (Beyotime Institute of Biotechnology, ShangHai, China), according to the manufacturer's instructions.

TNF- $\alpha$ level in the cell culture medium was measured via the Enzyme-linked immunosorbent assay (ELISA) kits (Shanghai Jianglai Biological Technology Co., LTD, ShangHai, China ) for chicken according to the manufacturer's instructions.

\section{Measuring the rates of reactive oxygen species (ROS)}

The levels of ROS in the cell culture medium were measured by ROS detecting kits (Nanjing Jiancheng Bioengineering Institute, Nanjing, China), according to the manufacturer's instructions by fluorometric analysis and cell's microscopic imaging analysis. In brief, cells $(1 \times 104$ per well) were incubated with $10 \mu \mathrm{M}$ DCFHDA reaction mixture for $30 \mathrm{~min}$ at $37^{\circ} \mathrm{C}$. The reaction mixture was poured out, and the cells were washed two times quickly with PBS. Cells were collected and re-suspended cells with $1 \mathrm{ml}$ PBS. Then, fluorescence intensity was measured using a multi-well microplate reader at an excitation wave length of $485 \mathrm{~nm}$ and emission wavelength of $528 \mathrm{~nm}$. The values were expressed as percentage of fluorescence intensity relative to control wells.

\section{Determination of the expression of apoptosis-related proteins by Western Blot Analysis}

The expression of apoptosis-related proteins (Fas and Caspase-8) was performed by Western blot according to the following methods: The total proteins of cells were extracted and mixed with equal volumes of sample buffer, heated for $4 \mathrm{~min}$ at $94^{\circ} \mathrm{C}$, subjected to $10 \%$ sodium dodecyl sulfate-polyacrylamide gel electrophoresis (SDS-PAGE) and transferred onto polyvinyl difluoride (PVDF) membranes. The PVDF membrane was rinsed in a TBST solution for $10 \mathrm{~min}$, after which a block of $2 \mathrm{~h}$ was performed by a blocking buffer. After the membrane was washed with the TBST solution 3 times, a primary monoclonal antibody (1:1000 dilution) (Santa Cruz Biotechnology, Inc ,Texas, USA ) was dissolved in the blocking buffer to a final concentration according to the manufacturer's instructions and added, and the membrane was incubated at room temperature for $2 \mathrm{~h}$. Then the membrane was rinsed with TBST solution 3 times. Following the manufacturer's instructions, a secondary antibody (Zhongshan Company, Beijing, China) was dissolved in the blocking buffer to a final concentration and added. Then, the membrane was incubated for 2 $h$, after which the membrane was rinsed with TBST solution 4 times.

Membranes were visualized using a chemiluminescence reagent kit (Santa Cruz Biotechnology, Inc, Texas, USA) and the images were produced and examined by a chemiluminescence imaging system, and the optical densities (ODs) of the target bands were analyzed via a gel imaging system.

\section{Statistical analysis}

A statistical analysis package ${ }^{f}$ was utilized to perform a one-way analysis of variance (one-way ANOVA), and the Duncan's multiple comparison test was used for the statistical analyses. $p<0.05$ was considered statistically significant. 


\section{RESULTS}

\section{Viability and apoptotic rate of peripheral lymphocytes}

Table 1 illustrates the effects of RES on the viability and apoptotic rate of peripheral lymphocytes induced by LPS in chickens. The results indicated that continuous stimulation by LPS could significantly decrease the viability of lymphocytes and increase the apoptotic rate $(p<0.05)$ as compared with the control. The application of different concentrations of RES $(20,40$, and $80 \mu \mathrm{l} / \mathrm{ml})$ could significantly increase the viability of lymphocytes and decrease the apoptotic rate in the treatment groups as compared with the RES-blank subgroup $(p<0.05)$.

Table 1 - Effects of RES on the viability and apoptotic rate of chicken peripheral lymphocytes stimulated by LPS.

\begin{tabular}{|c|c|c|c|c|c|c|}
\hline $\begin{array}{l}\text { Treatments } \\
\text { Variable }\end{array}$ & $\mathrm{LPS}+0 \mu \mathrm{g} / \mathrm{ml} \mathrm{RES}$ & LPS $+20 \mu \mathrm{g} / \mathrm{ml}$ RES & LPS $+40 \mu \mathrm{g} / \mathrm{ml}$ RES & LPS $+80 \mu \mathrm{g} / \mathrm{ml}$ RES & SEM & $p$ \\
\hline Apoptotic rate & $5.107^{a}$ & $4.117^{b}$ & $3.780^{\mathrm{bc}}$ & $3.927^{b c}$ & 0.145 & 0.00 \\
\hline Lymphocytes viability & $0.065^{c}$ & $0.072^{b}$ & $0.078^{a b}$ & $0.079 \mathrm{ab}$ & 0.002 & 0.01 \\
\hline
\end{tabular}

Note: Different letters in same raw indicate significant difference $(p<0.05)$.

\section{Activity of NF-kB levels of TNF- $\alpha$ and ROS}

Table 2 displays the effects of RES on the induced by LPS activity of NF-KB levels of TNF- $\alpha$ and ROS in the culture medium of chicken peripheral lymphocytes. The results demonstrated that continuous stimulation by LPS could significantly increase the activity of NF$\mathrm{KB}$ levels of TNF- $\alpha$ and ROS as well $(p<0.05)$. The activity of NF-KB levels of TNF- $\alpha$ and ROS in the RES treatment subgroups $(20,40$, and $80 \mu \mathrm{l} / \mathrm{ml}$ of RES) was significantly decreased in comparison with that in the RES-blank subgroup $(p<0.05)$.

Table 2 - Effects of RES on NF-KB activity level of TNF- $\alpha$ and ROS in the peripheral blood lymphocyte culture fluid of chicken provoked by LPS.

\begin{tabular}{|c|c|c|c|c|c|c|}
\hline $\begin{array}{l}\text { Treatments } \\
\text { Variable }\end{array}$ & $\mathrm{LPS}+0 \mu \mathrm{g} / \mathrm{ml} \mathrm{RES}$ & $\mathrm{LPS}+20 \mu \mathrm{g} / \mathrm{ml} \mathrm{RES}$ & $\mathrm{LPS}+40 \mu \mathrm{g} / \mathrm{ml}$ RES & $\mathrm{LPS}+80 \mu \mathrm{g} / \mathrm{ml} \mathrm{RES}$ & SEM & $p$ \\
\hline NF-KB & $2.973^{a}$ & $2.563^{b}$ & $2.357^{b c}$ & $2.320^{\mathrm{cd}}$ & 0.082 & 0.00 \\
\hline TNF- $\alpha$ & $73.37^{a}$ & $60.30^{b}$ & $59.20^{b}$ & $58.63^{b}$ & 1.703 & 0.00 \\
\hline ROS & $880.3^{a}$ & $739.3^{b}$ & $706.0^{b}$ & $708.3^{b}$ & 29.39 & 0.00 \\
\hline
\end{tabular}

Note: Different letters in same raw indicate significant difference $(p<0.05)$.

\section{Expression of apoptosis-related proteins in the lymphocytes}

Table 3 shows the effects of RES on the expression of Fas and Caspase-8, instigated by LPS in the culture medium of chicken peripheral lymphocytes. The results evidenced that continuous stimulation by LPS could significantly increase the relative expression of the apoptosis-related proteins Fas and Caspase- 8 $(p<0.05)$. The cells in the treatment group that had been treated with 20,40 and $80 \mu \mathrm{l} / \mathrm{ml}$ of RES exhibited a significantly lower Fas and Caspase-8 expression level than that in the RES-blank subgroup $(p<0.05)$. Similarly, the cells in the group treated with 40 or $80 \mu \mathrm{l} / \mathrm{ml}$ of RES demonstrated a significantly lower Caspase-8 expression level in comparison to that of the $20 \mu \mathrm{l} / \mathrm{ml}$ RES subgroup $(p<0.05)$.

Table 3 - Impact of RES on the expression of apoptosis-related proteins inflicted by LPS in the fluid of the culture medium of chicken peripheral lymphocytes.

\begin{tabular}{|c|c|c|c|c|c|c|}
\hline $\begin{array}{l}\text { Treatments } \\
\text { Variable }\end{array}$ & $\mathrm{LPS}+0 \mu \mathrm{g} / \mathrm{ml} \mathrm{RES}$ & $\mathrm{LPS}+20 \mu \mathrm{g} / \mathrm{ml} \mathrm{RES}$ & $\mathrm{LPS}+40 \mu \mathrm{g} / \mathrm{ml} \mathrm{RES}$ & $\mathrm{LPS}+80 \mu \mathrm{g} / \mathrm{ml} \mathrm{RES}$ & SEM & $p$ \\
\hline Fas & $1317^{a}$ & $1162^{b}$ & $1088^{b}$ & $1109^{b}$ & 29.70 & 0.00 \\
\hline Caspase-8 & $2239^{a}$ & 1939 b & $1659^{c}$ & $1815 b^{c}$ & 111.1 & 0.00 \\
\hline
\end{tabular}

Note: Different letters in same raw indicate significant difference $(p<0.05)$.

\section{DISCUSSION}

The number and activity of lymphocytes are important indicators for the evaluation of immune functions in chickens and mammals (Finlay \& Cossart, 1997). The increased apoptotic rate of lymphocytes could decrease lymphocyte count and inhibit immune functions (Zorrilla, et al., 2001; Ato, et al., 2013). Cell apoptosis is a process of a programmed cell death, which is a positive self-killing method of the cells, triggered by certain physiological or pathological conditions and regulated by internal and external microenvironment 
factors alone, or in complicated interactions with multiple cellular regulatory genes. Initiation of a cell apoptosis involves the activation, expression, and regulation of a series of genes. Disorders in cellular apoptosis could be directly or indirectly associated with a number of diseases. Several bacteria, as well as other pathogens and LPS induce immunological stress, inflammatory responses, and oxidative DNA damages in cells, leading to the escalated apoptosis of immune cells, decreased cell counts, and finally causing immune dysfunctions (Watanabe, et al., 2003; Bowen, et al., 2009). The long-term stress elicits the expression of the cellular death receptor Fas, which increases the sensitivity of lymphocytes to apoptosis, and thus reduces the cell count of lymphocytes and downregulate immunosuppression (Yin, et al., 2000; Silberman et al., 2002). In the present study, the mechanisms involved in the apoptosis of the lymphocytes, provoked by the application of LPS, were investigated.

On the one hand, the LPS stimulation could significantly increase the levels of TNF- $\alpha$ and ROS in the culture medium of chicken peripheral lymphocytes, damage the cellular structure, and induce the apoptosis of lymphocytes; on the other hand, TNF- $\alpha$ and ROS are extracellular stimuli that could activate NF-KB, which in turn could increase the expression of the cellular death receptor Fas and the pro-apoptotic gene Caspase-8, and thus initiate the Fas signaling pathway in lymphocytes, leading to an elevated apoptotic rate of the lymphocytes, and reduced overall lymphocyte count and viability. RES caused a decline in the production of inflammatory factors and ROS, and thus limited the cellular damages caused by these influences (Gao, et al., 2011; Yan, et al., 2011); in addition, RES also inhibited the activation of NF-KB by these extracellular signals (Ashutosh, et al., 2010).

In this investigation, we found that the application of RES significantly lowered the levels of TNF- $\alpha$ and ROS, as well as the activity of NF-kB in the culture medium of chicken peripheral lymphocytes $(P<0.05)$. Furthermore, the expression of Fas and Caspase- 8 in the cells was also downregulated, which decreased the level of the LPS-induced apoptosis of the chicken peripheral lymphocytes. The mechanisms involved in the NF- $\mathrm{KB}$ reduction effects caused by the RES treatment could be associated with the anti-inflammatory and antioxidative effects, which led to a decline in the extracellular signals, including the activities of TNF- $\alpha$ and ROS. In turn, this decreased the activation of NF$K B$, the transcription and biological syntheses of Fas and Caspase-8, and the apoptosis of lymphocytes.
These findings provide evidence that at a cellular and protein level RES could negatively regulate the apoptosis of chicken peripheral lymphocytes induced by LPS. The results of this study could provide valuable theoretical evidence and a practical contribution to the determination of the exact regulation mechanisms of lymphocyte apoptosis caused by stress. In summary, RES inhibited the production of extracellular signal factors, including TNF- $\alpha$ and ROS, reduced the activation of NF-KB, and consequently downregulated the transcription and biological syntheses of Fas and Caspase-8, leading to the protection of the chicken peripheral lymphocytes from LPS-induced apoptosis.

\section{ACKNOWLEDGEMENTS}

This work was supported in part by the NSFC-Joint Research Fund of Henan (U1404323); the Research Foundation for Advanced Talents in Henan University of Technology (31400371); the Basic Scientific Research Project of Henan University of Technology (2014JCYJ11)

\section{REFERENCES}

Ashutosh K, Shyam S, NF-kB inhibitory action of resveratrol: A probable mechanism of neuroprotection in experimental diabetic neuropathy. Biochemical and Biophysical Research Communications 2010;394:360365 .

Ato M, Takahashi Y, Fujii H, Hashimoto S, Kaji T, Itamura S, et al. Influenza A whole virion vaccine induces a rapid reduction of peripheral blood leukocytes via interferon- $\alpha$-dependent apoptosis. Vaccine 2013;19:2184-2190.

Barkett M, Gilmore TD, Control of apoptosis by Rel/NF-kappaB transcription factors. Oncogene 1999;22:6910-6924.

Ben SV, Sofer Y, Bergman M, Zurovsky Y, Grossman S. Lipopolysaccharideinduced oxidative stress in the liver: comparison between rat and rabbit. Shock 1999;12:288-293.

Bowen OT, Dienglewicz RL, Wideman RF. Altered monocyte and macrophage numbers in blood and organs of chickens injected i.v. with lipopolysaccharide. Veterinary Immunology and Immunopathology 2009; 131:200-210

Finlay BB, Cossart P. Exploitation of mammalian host cell functions by bacterial pathogens. Science 1997;276:718-725.

Gao X, Xu YX, Janakiraman N, Chapman RA, Gautam SC. Immunomodulatory activity of resveratrol: suppression of lymphocyte proliferation, development of cell-mediated cytotoxicity, and cytokine production. Biochemical Pharmacology 2011;1:1299-1308.

Hsieh T, Halicka D, Lu XH, Kunicki J, Guo JQ, Darzynkiewicz Z, et al. Effects of resveratrol on the G0-G1 transition and cell cycle progression of mitogenically stimulated human lymphocytes. Biochemical and Biophysical Research Communications 2002;297:1311-1317.

Lappin E, Ferguson AJ. Gram-positive toxic shock syndromes. Lancet Infectious Diseases 2009;9:281-290. 
Lawrence L, Bebien M, George Y. IKKa limits macrophage NF-kB activation and contributes to the resolution of inflammation. Nature 2005;434:1138-1143.

Manna SK, Mukhopadhyay A, Aggarwal BB. Resveratrol suppresses TNFinduced activation of nuclear transcription factors NF-kappa B, activator protein-1, and apoptosis:potential role of reactive oxygen intermediates and lipid peroxidation. Journal Immunology 2000;15:6509-19.

Rodrigues VS, Vidotto MC, Felipe I, Santos DS, Gaziri L C J, Apoptosis of murine peritoneal macrophages induced by an avian pathogenic strain of escherichia coli. Microbiology Letters 1999;179:73-78.

Sahin K, Akdemir F, Orhan C, Tuzcu M, Hayirli A, Sahin N. Effects of dietary resveratrol supplementation on egg production and antioxidant status. Poultry Science 2010;89:1190-1198.

Sahin K, Orhan C, Akdemir F, Tuzcu M, Iben C, Sahin N. Resveratrol protects quail hepatocytes against heat stress: modulation of the Nrf2 transcription factor and heat shock proteins. Journal of Animal Physiology and Animal Nutrition 2012;96:66-74.

Seo K, Seo S, Han JY, Ki SH, Shin SM. Resveratrol attenuates methylglyoxalinduced mitochondrial dysfunction and apoptosis by Sestrin2 induction[J]. Toxicology and Applied Pharmacology 2014;280(2):314322.

Shakibaei M, Csaki C, Nebrich S, Mobasheri A. Resveratrol suppresses interleukin-1 $\beta$-induced inflammatory signaling and apoptosis in human articular chondrocytes:potential for use as a novel nutraceutical for the treatment of osteoarthritis[J]. Biochemical Pharmacology 2008;76(11):1426-1439.

Shini S, Kaiser P, Shini A. Bryden WL Differential alterations in ultrastructural morphology of chicken heterophils and lymphocytes induced by corticosterone and lipopolysaccharide. Veterinary Immunology and Immunopathology 2008;122(1):83-93.

Silberman DM, Wald M, Genaro AM. Effects of chronic mild stress on lymphocyte proliferative response. Participation of serum thyroid hormones and corticosterone. International Immunopharmacology 2002;2:487-497

Spurlock M E. Regulation of metabolism and growth during immune challenge: an overview of cytokine function. Journal of Animal Science $1997 ; 75(7): 1773-1783$.
Tsai SH, Lin SY, Lin JK. Suppression of nitric oxide synthase and the downregulation of the activity of NF-kB in macrophages by resveratrol. British Journal of Pharmacology 1999;126:673-680.

Watanabe K, Jinnouchi K, Inai S, Yagi T. Induction of apoptosis in the vestibule of guinea pigs after middle ear inoculation with lipopolysaccharide (LPS). Auris Nasus Larynx 2003;30:355-361.

Watanabe K, JinnouchiK, Inai S, Yagi T, Induction of apoptosis in the vestibule of guinea pigs after middle ear inoculation with lipopolysaccharide (LPS). Auris Nasus Larynx 2003;30:355-361.

Wiang W, Li P, Xu J, Wu X, Guo Z, Fan L, et al. Resveratrol attenuates high glucose-induced nucleus pulposus cell apoptosis and senescence through activating the ROS-mediated PI3K/Akt pathway [J]. Bioscience Reports 2017;38(2):BSR20171454

Yan Y, Yang JY, Chen GL, Mou YH, Zhao YA. Protection of resveratrol and its analogues against ethanol-induced oxidative DNA damage in human peripheral lymphocytes. Mutation Research 2011;721:171-177.

Yi C O, Jeon BT, Shin HJ, Jeong EA, Chang KC, Lee JE, et al. Resveratrol activates AMPK and suppresses LPS-induced NF-KB-dependent COX-2 activation in RAW 264.7 macrophage cells. Anatomy \& Cell Biology 2011;44(3):194-203.

Yin D, David TR, Allan M, Shi Y.F. Chronic Restraint Stress Promotes Lymphocyte Apoptosis by Modulating Cd95 Expression. Journal of Experimental Medicine 2000;191:1423-1428.

Yun JM, Chien A, Jialal I, Devaraj S. Resveratrol up-regulates SIRT1 and inhibits cellular oxidative stress in the diabetic milieu: mechanistic insights. Journal of Nutritional Biochemistry 2012;23:699-705

Zhang J, Chen J, Yang J, Xu CW, Pu P, Ding JW, et al. Resveratrol Attenuates Oxidative Stress Induced by Balloon Injury in the Rat Carotid Artery Through Actions on the ERK $1 / 2$ and NF- $k$ B Pathway. Cellular Physiology and Biochemistry 2013;14:230-241.

Zhang $Q$, Waqas $Y$, Yang $P$, et al. Cytological study on the regulation of lymphocyte homing in the chicken spleen during LPS stimulation[J]. Oncotarget 2017;8(5):7405.

Zorrilla EP, Luborsky L, McKay JR, Rosenthal R, Houldin A, Tax A, et al. The relationship of depression and stressors to immunological assays: a meta-analytic review. Brain Behavior and Immunity 2001;15:199-226. 